\title{
PENGARUH MEDIA TANAM SABUT KELAPA (Cocopeat) DAN PUPUK KANDANG TERHADAP PERTUMBUHAN DAN PRODUKSI TANAMAN CABAI RAWIT (Capsicum Frutencens L).
}

\author{
Yusriani $\mathbf{N}^{1}$, Pardi Tammin $\mathbf{T}^{2}$ \\ ${ }^{1}$ Program Studi Agroteknologi, Fakultas Pertanian, Universitas \\ Graha Nusantara Padangsidimpuan \\ Bukit Simarsayang Kampus 1 Padangsidimpuan \\ email: yusrianinasution17@gmail.com \\ 2 Program Studi Agroteknologi, Fakultas Pertanian, Universitas \\ Graha Nusantara Padangsidimpuan \\ Bukit Simarsayang Kampus 1 Padangsidimpuan \\ Email: pardytammin57@gmail.com
}

Submitted: 14 Januari 2022 Accepted: 20 Februari 2022 Approved: 21 Februari 2022

\section{ABSTRAK}

Penelitian ini bertujuan untuk mengetahui pengaruh pemberian sabut kelapa (Cocopeat), dan pupuk kandang terhadap pertumbuhan dan produksi tanaman cabai rawit. Penelitian ini dilaksanakan di Kampus 1 Torsimarsayang Fakultas Pertanian Universitas Graha Nusantara kota Padangsidimpuan. Penelitian ini menggunakan metode Rancangan Acak Kelompok (RAK) non Faktorial dengan 4 (empat) perlakuan dan 6 (enam) ulangan. Perlakuan antara lain : P0 (tanah $5 \mathrm{~kg}$ kontrol), P1 (tanah $5 \mathrm{~kg}+70 \mathrm{~g}$ Cocopeat /pot), P2 (tanah $5 \mathrm{~kg}+70 \mathrm{~g}$ Cocopeat $+70 \mathrm{~g}$ kotoran kambig/pot), P3 (tanah $5 \mathrm{~kg}+70 \mathrm{~g}$ Cocopeat $+700 \mathrm{~g}$ kotoran sapi/pot). Parameter yang diuji yaitu tinggi tanaman, jumlah daun dan produksi perpot. Data yang diperoleh dianalisa secara statistik dengan uji ANOVA (Analysis of Varians) pada $\alpha=5 \%$ dan dilanjutkan dengan uji Beda Jarak Nyata Duncan (Duncan's Multiple Range Test). Hasil penelitian menunjukkan perlakuan media tanam (Cocopeat) dan berbagai jenis pupuk kandang berpengaruh nyata terhadap pertumbuhan tinggi tanaman dan jumlah daun. Dengan demikian perlakuan media tanam cocopeat dan pupuk kandang memberikan pengaruh yang nyata terhadap pertumbuhan cabai rawit.

Kata kunci: Cabai rawit, cocopeat, pupuk kandang.

\section{ABSTRACT}

This study aims to determine the effect of awarding cocopeat and manure on the growth and production of cayenne pepper plants. The research was carried out at Campus Torsimarsayang, Faculty of Agriculture, University of Graha Nusantara, Padangsidimpuan. This study used a nonfactorial Randomized Block Design (RAK) method with 4 (four) treatments and 6 (six) replications. The treatments were: $P 0$ (control), $P 1$ (5 kg soil $+70 \mathrm{~g}$ Cocopeat $/$ pot), $P 2$ (5 kg soil $+70 \mathrm{~g}$ Cocopeat +70 $g$ goat manure/pot), $P 3$ (5 kg soil $+70 \mathrm{~g}$ Cocopeat $+70 \mathrm{~g}$ cow manure/pot). Observations included plant height, number of leaves and plant production. The data obtained were analyzed statistically with 5\% ANOVA (Analysis of Variance) test and continued with Duncan's Multiple Range Test. The results showed that the treatment of planting media (Cocopeat) and various types of manure had a significant effect on the growth of plant height and number of leaves. Thus, the treatment of cocopeat growing media and manure gave a significant effect on the growth of cayenne pepper.

Keywords : Cayenne pepper, cocopeat, manure.

\section{PENDAHULUAN}

Cabai rawit (Capsicum frutescens $\mathrm{L}$ ) merupakan salah satu tanaman hortikultura dari jenis sayuran yang memiliki buah kecil dengan rasa yang pedas. Selain itu tanaman ini mempunyai banyak manfaat terutama pada buahnya, yaitu sebagai bumbu masak, bahan campuran industri makanan, dan sebagai bahan kosmetik (Ashari, 1995). Harganya lebih mahal dari cabai biasa namun banyak petani yang mengalami gagal panen. Terjadinya gagal panen diakibatkan beberapa kendala, terutama tingkat kesuburan tanah dan hama yang berkembang di tengah udara lembab sehingga membuat bunga, daun dan tanaman cabai rawit rusak akhirnya mengakibatkan kegagalan panen (Supriyanto, 2012). 
Dalam kegiatan budidaya, media merupakan salah satu faktor penting untuk menunjang keberhasilan. Media tanam merupakan bahan yang digunakan untuk pembibitan yang berfungsi sebagai penyimpanan unsur hara atau nutrisi, mengantur kelembaban dan suhu udara serta berpengaruh terhadap proses pembentukan akar. (Putri, et al., 2013). Selain itu bertanam cabai pada lahan yang luas pertanaman juga dapat dilakukan dalam polybag. Hal ini merupakan alternatif pemecahan masalah bila membutuhkan buah cabai segar (S. Rahman, 2010).

\begin{abstract}
Salah satu upaya untuk mempertahankan dan meningkatkan kesuburan tanah adalah dengan pemberian bahan organik seperti cocopeat maupun pupuk kandang ke dalam tanah. Souri (2001) menyatakan bahwa pupuk kandang merupakan kotoran padat dan cair dari hewan yang tercampurdengan sisa-sisa pakan dan alas kandang (Souri, 2001). Cocopeat merupakan hasil olahan sabut kelapa, cocopeat dijadikan salah satu media tanam karena memiliki kandungan unsur hara yang sangat dibutuhkan dan sangat bermanfaat karena menyerap air dan unsur hara lebih banya. Menurut Abad et al (2002) bahwa cocopeat merupakan komponen media tanam yang baik dengan $\mathrm{pH}$ yang dapat diterima, konduktivitas listrik dan bahan kimia lainnya.
\end{abstract}

Diantara berbagai pupuk kandang, kotoran sapi merupakan salah dari pupuk dingin. Kandungan $\mathrm{N}, \mathrm{P}_{2} \mathrm{O}_{5}$ serta $\mathrm{K}_{2} \mathrm{O}$ yang terdapat dalam pupuk kandang dari sapi adalah 0,60\%; 0,15\%; 0,45\% (Sutejo, 1995). Sebagaimana di katakan oleh (Sarido, 2013) bahwa kelebihan pupuk kandang sapi atau pupuk organik lainnya akan mampu merubah struktur tanah menjadi lebih baik bagi perkembangan perakaran, meningkatkan daya pegang dan daya serap tanah terhadap air, memperbaiki kehidupan organisme dalam tanah dan menambah unsur hara di dalam tanah. Menurut Qibtiyah et al (2021) Pupuk kandang sebagai bahan organik menjadi alternatif pengganti dalam penggunaan pupuk an organik.

Dibandingkan dengan kotoran sapi, kotoran kambing mempunyai kadar hara $\mathrm{N}$ lebih tinggi dari kotoran hewan yang lain yaitu $2,43 \%$. Nitrogen yang tinggi ini bisa digunakan dalam menjaga kesuburan tanah. Penelitian Awodun (2007) menunjukkan kotoran kambing secara signifikan dapat memperbaiki ketersediaan unsur hara dan status kesuburan tanah, serta pertumbuhan pada tanaman lada di mana pada dosis sebesar 10 ton ha ${ }^{-1}$ dapat meningkatkan sumber $\mathrm{N}, \mathrm{P}, \mathrm{K}, \mathrm{Ca}$, dan $\mathrm{Mg}$ dan bahan organik untuk produksi lada. Selain itu, pada penelitian Rahayu et al. (2014) dilaporkan bahwa pemberian kotoran kambing pada dosis 15 ton ha ${ }^{-1}$ dapat meningkatkan pertumbuhan tanaman bawang daun dan wortel.

Sekarang ini sabut kelapa, kotoran kambing maupun kotoran sapi masih belum dimanfaatkan secara optimal dikalangan masyarakat dan hanya menjadi limbah dibidang pertanian, sehingga pemanfatan limbah dalam bentuk cocopeat sangat membantu dalam proses siklus organik dan peningkatan ketersediaan hara bagi pertumbuhan dan produksi cabe rawit. Pemanfaatan limbah sabut kelapa (cocopeat) dan kotoran sapi sangat perlu dilakukan pada media tanam cabe rawit di dalam polybag sehingga budidaya dapat dilakukan pada lahan terbatas dengan hasil panen yang meningkat.

Tujuan penyusunan artikel ilmiah ini yaitu untuk mengetahui pengaruh pemberian antara sabut kelapa (Cocopeat), pupuk kandang kotoran kambing dan kotoran sapi terhadap pertumbuhan dan produksi tanaman cabai rawit, dapat dijadikan salah satu pemecahan masalah ketergantungan terhadap penggunaan pupuk kimia.

\section{METODE PENELITIAN}

Penelitian ini dilaksanakan di Kampus 1 Torsimarsayang Fakultas Pertanian Universitas Graha Nusantara Kecamatan Padangsidimpuan Utara Kota Padangsidimpuan Sumatera Utara mulai bulan September 2020 sampai Januari 2021. Tanah yang digunakan adalah Inceptisol dengan ketinggian tempat $520 \mathrm{~m}$ dpl dan curah hujan $2210 \mathrm{~mm} / \mathrm{th}$.

Alat yang digunakan dalam penelitian ini adalah handtraktor, tangki penyemprot, parang, handsprayer, alat tulis menulis, tali rafia, mistar/meteran, papan label, gelas ukur, ember plastik dan cangkul. Sedangkan bahan yang digunakan dalam penelitian ini adalah cabe rawit varietas hibrida, sabut kelapa (Cocopeat), pupuk kandang kotoran kambing dan kotoran sapi.

\section{Rancangan Penelitian}

Penelitian ini menggunakan Rancangan Acak Kelompok (RAK) non faktorial, dengan 4 tingkat taraf perlakuan 
dan Penelitian ini diulang sebanyak 6 kali dengan perlakuan sebagai berikut yaitu:

$$
\begin{aligned}
& \mathbf{P}_{\mathbf{0}} \quad=\text { Tanah } 5 \mathrm{~kg} \text { ( kontrol ) / Pot } \\
& \mathbf{P}_{1}=\text { Tanah } 5 \mathrm{~kg}+70 \mathrm{~g} \text { Sabut kelapa } \\
& \text { (Cocopeat)/ Pot } \\
& \mathbf{P}_{2} \quad=\text { Tanah } 5 \mathrm{~kg}+70 \mathrm{~g} \text { Sabut kelapa } \\
& \text { (Cocopeat) + } 70 \mathrm{~g} \text { Kotoran } \\
& \text { kambing/Pot } \\
& \mathbf{P}_{\mathbf{3}}=\text { Tanah } 5 \mathrm{~kg}+70 \mathrm{~g} \text { sabut kelapa } \\
& \text { (Cocopeat) + } 70 \mathrm{~g} \text { Kotoran } \\
& \text { Sapi/Pot }
\end{aligned}
$$
memasukan ke dalam pot dengan pencampuran pupuk kandang dan sabut kelapa (Cocopeat) per pot. Selanjutnya media di aplikasikan sesuai dengan perlakuan, setelah dilakukan pencampuran tanah dengan pupuk kandang dan cocopeat tanah dibiarkan 2 minggu baru dilakukan penanaman. Penanaman dilakukan setelah umur semai tanaman cabai rawit 21 hari disemai dengan kedalaman $\pm 3 \mathrm{~cm}$ dengan jarak tanam antar lubang sesuai jarak tanam penelitian. Parameter yang diamati antara lain tinggi tanaman, diameter batang, jumlah cabang, jumlah bunga, jumlah buah, diameter buah, dan berat buah.

\section{HASIL DAN PEMBAHASAN \\ Tinggi tanaman $(\mathrm{cm})$}

Hasil penelitian pengaruh media tanam sabut kelapa (Cocopeat) dan berbagai jenis pupuk kandang terhadap tinggi tanaman cabai rawit (capsicum frutencens $\mathrm{L}$ ) terdapat hasil yang berbeda pada setiap pengamatan 1 mst sampai pengamatan $7 \mathrm{mst}$. Tinggi tanaman cabai rawit (capsicum frutencens $\mathrm{L}$ ) pada media tanam sabut kelapa (Cocopeat) dan berbagai jenis pupuk kandang dapat dilihat pada hasil uji lanjut (tabel 1).

Tabel 1. Rata - rata tinggi tanaman cabai Tabe

\begin{tabular}{ccccc}
\multicolumn{5}{c}{ rawit(cm) } \\
\hline \multicolumn{4}{c}{ Perlakuan } & \multicolumn{3}{c}{$\begin{array}{c}\text { Umur pengamatan minggu setelah } \\
\text { tanam (mst) }\end{array}$} & V & VI & VII \\
\hline P0 & $14.17 \mathrm{~b}$ & $16.17 \mathrm{~b}$ & $17.83 \mathrm{~b}$ & $19.17 \mathrm{~b}$ \\
P1 & $13.00 \mathrm{~b}$ & $15.67 \mathrm{~b}$ & $17.67 \mathrm{~b}$ & $19.33 \mathrm{~b}$ \\
P2 & $22.50 \mathrm{a}$ & $24.83 \mathrm{a}$ & $26.83 \mathrm{a}$ & $28.83 \mathrm{a}$ \\
P3 & $16.00 \mathrm{~b}$ & $18 \mathrm{~b}$ & $20.17 \mathrm{~b}$ & $22.17 \mathrm{~b}$ \\
\hline
\end{tabular}

Keterangan : Angka-angka yang diikuti oleh huruf kecil yang sama pada kolom yang sama adalah tidak berbeda nyata pada uji Duncan $5 \%$.
Berdasarkan tabel statistik deskriptif tinggi tanaman cabai rawit, bahwa terdapat pengaruh nyata dari jenis media tanam terhadap pertambahan tinggi tanaman cabai rawit. Rerata tinggi tanaman yang terbaik terdapat pada media P2 (tanah:sabut kelapa:pupuk kandang kotoran kambing) hal ini disebabkan unsur hara yang terkandung dalam pupuk kandang kambing lebih lama tertahan pada media sabut kelapa sehingga tanaman lebih banyak memperoleh nutrisi dari media P3 (tanah:sabut kelapa:pupuk kandang kotoran sapi) yang menyebabkan tanaman cabai rawit pada media P2 lebih tinggi dari pada media lainnya. Kotoran kambing memiliki kandungan $\mathrm{N}$-total yang cukup tinggi sehingga kotoran kambing dapat menyumbangkan nitrat lebih besar dibandingkan dengan perlakuan lainnya. Hasil penelitian yang sama juga pada Tria Santari et al. (2019) bahwa tinggi tanaman tertinggi adalah pada perlakuan pemberian pupuk kotoran kambing. Sejalan dengan hasil penelitian Silvia et al. (2012) yang melaporkan bahwa pemberian kotoran kambing dengan dosis 15 ton ha- 1 pada cabe diperoleh tinggi tanaman tertinggi pada umur 35 dan 42 HST. Hal ini membuktikan bahwa pemberian cocopeat dan kotoran kambing dapat memenuhi kebutuhan hara yang sama dengan pemberian pupuk standar untuk menunjang pertumbuhan vegetatif dari tanaman cabai rawit.

\section{Jumlah daun (helai)}

Hasil penelitian pengaruh media tanam sabut kelapa (Cocopeat)dan berbagai jenis pupuk kandang terhadap jumlah daun cabai rawit (capsicum frutencens $L$ ) terdapat hasil yang berbeda - beda setiap perlakuan pengamatan 4 mst sampai pengamatan 7 mst. Jumlah daun cabai rawit (capsicum frutencens $L$ ) akibat dari pengaruh media tanam sabut kelapa (Cocopeat) dan berbagai jenis pupuk kandang dapat dilihat pada hasil uji lanjut (tabel 2).

Tabel 2.Rata - rata jumlah daun tanaman cabai rawit (helai)

\begin{tabular}{ccccc}
\hline Perlakuan & \multicolumn{4}{c}{$\begin{array}{c}\text { Umur pengamatan minggu setelah } \\
\text { tanam (mst) }\end{array}$} \\
& IV & $\mathrm{V}$ & $\mathrm{VI}$ & VII \\
\hline P0 & $8.67 \mathrm{c}$ & $12.33 \mathrm{c}$ & $16.5 \mathrm{c}$ & $20.67 \mathrm{~b}$ \\
P1 & $11.5 \mathrm{bc}$ & $14.83 \mathrm{bc}$ & $19.83 \mathrm{bc}$ & $24 \mathrm{~b}$ \\
P2 & $23.67 \mathrm{a}$ & $27.33 \mathrm{a}$ & $32.83 \mathrm{a}$ & $38 \mathrm{a}$ \\
P3 & $17.67 \mathrm{ab}$ & $21.5 \mathrm{ab}$ & $26.83 \mathrm{ab}$ & $31.83 \mathrm{a}$
\end{tabular}

Keterangan : Angka-angka yang diikuti oleh huruf kecil yang sama pada kolom yang sama adalah tidak berbeda nyata pada uji Duncan 5\%. 
Pada tabel 2 dapat dilihat bahwa pertumbuhan terbaik pada jumlah daun tanaman cabai rawit adalah pada perlakuan P2 (tanah:cocopeat:pupuk kandang kotoran kambing) dan P3 (tanah:cocopeat:pupuk kandang kotoran sapi), antara P2 dan P3 adalah tidak berbeda nyata. Perlakuan P2 berbeda nyata dengan perlakuan P0 (kontrol) dan Perlakuan P1 (tanah:cocopeat). Dari hasil penelitian jelas terlihat perlakuan cocopeat dengan pupuk kandang (P2 dan P3) mempunyai pengaruh yang nyata terhadap perlakuan P0. Hasil dekomposisi bahan organik pada perlakuan P2 dan P3 menguraikan hara yang lebih tersedia bagi pertumbuhan jumlah helai daun tanaman cabai rawit. Hal ini disebabkan ketersediaan hara yang tinggi pada pemberian cocopeat dan kotoran kambing dan juga cocopeat dengan kotoran sapi dapat meningkatkan ketersediaan hara tanah Inceptisol yang rendah sehingga dapat mendukung pertumbuhan tanaman cabai rawit.

Penelitian ini sejalan dengan hasil dari (Rizwan, 2008 ; Tria Santari, 2019; Hamkari Salam, 2018) yang menyatakan bahwa perombakan kotoran kambing mengalami proses dekomposisi dan mineralisasi, sehingga ketersediaan hara lebih tinggi dan memberikan pengaruh nyata pada jumlah daun tanaman. Sofiarani dan Erlina (2020) juga menyatakan bahwa penggunaan media tanam dengan cocopeat pada pertumbuhan dan produksi tanaman cabai rawit menghasilkan perbedaan yang nyata dengan hasil pengamatan terhadap kontrol. Dengan demikian campuran bahan cocopeat dan pupuk kandang dapat mempercepat perombakan bahan organik menjadi hara tersedia bagi pertumbuhan tanaman cabai rawit.

\section{Berat Buah per Tanaman (g)}

Hasil penelitian pengaruh media tanam sabut kelapa (Cocopeat) dan berbagai jenis pupuk kandang terhadap berat buah cabai rawit (capsicum frutencens $L$ ) terdapat hasil yang berbeda - beda. Jumlah produksi cabai rawit (capsicum frutencens $L$ ) akibat dari pengaruh media tanam sabut kelapa (Cocopeat) dapat dilihat pada tabel 3.
Tabel 3. Rata - rata berat buah (g)

\begin{tabular}{cc}
\hline Perlakuan & $\begin{array}{l}\text { Rataan berat buah/tan } \\
(\mathrm{g})\end{array}$ \\
\hline P0 & $178.33 \mathrm{a}$ \\
P1 & $198.33 \mathrm{a}$ \\
P2 & $216.67 \mathrm{a}$ \\
P3 & $188.33 \mathrm{a}$ \\
\hline
\end{tabular}

Berdasarkan Tabel 3. secara kuantitatif hasil tertinggi pada pengamatan berat buah/tanaman yaitu pada P2 ( tanah :sabut kelapa cocopeat: kotoran kambing) dan yang paling rendah adalah PO (kontrol), walaupun uji statistik menyatakan tidak berbeda nyata antara semua perlakuan. Banyaknya buah yang dihasilkan per tanaman menggambarkan bahwa tanaman tersebut semakin produktif. Hal yang sama dilaporkan oleh Bere et al. (2020) bahwa rerata yang paling tinggi pada berat buah per tanaman cabe rawit terdapat pada dosis pupuk organik 15 ton/ha pada perlakuan pupuk kotoran kambing.

\section{KESIMPULAN}

Perlakuan P2 yaitu media dengan kombinasi tanah $5 \mathrm{~kg}$ : cocopeat 28 ton ha ${ }^{-1}$ : pupuk kandang kambing 28 ton $\mathrm{ha}^{-1}$ memberikan pengaruh nyata pada tinggi tanaman dan jumlah daun pada tanaman cabai rawit. Secara kuantitatif respon tertinggi buah per tanaman cabai rawit adalah terhadap perlakuan P2 (tanah: cocopeat: kotoran kambing)

\section{DAFTAR PUSTAKA}

Abad, M., P. Noguera, R. Puchades, A. Maquieira and V. Noguera, 2002. Physico-chemical and chemical properties of some coconut dusts for use as a peat substitute for containerized ornamentalplants.Biores.Technol.,82: 241-

245.http://cat.inist.fr/?aModele=affich eN\& cpsidt=1355 1255.

Ashari, S., 1995, Hortikultura Aspek Budaya cetakan 1, Universitas Indonesia Press, Jakarta.

Awodun MA. 2007. Effect of goat manure and urea fertilizer on soil, growth and yield of okra (Abelmoschus esculentus (L.) 
Moench). International Journal of Agricultural Research. 2: 632-636. https://doi.org/10.3923/ijar.2007.632. 636.

Bere, D., Yekti M dan Darnawi. 2020. Pengaruh Macam dan Dosis Pupuk Kandang Terhadap Pertumbuhan dan Produksi Tanaman Cabai Rawit (Capsicum frutescens L.)

Hamkary Salam M. 2018. Pemanfaatan Biochar dan Pupuk Kandang Kambing untuk Ketersesiaan Nitrogen, Pertumbuhan dan Hasil Tanaman Cabai Rawit. Skripsi. Fakultas Pertanian Universitas Mataram.

Putri, A. D., Sudiarso, \& Islami, T. (2013). Pengaruh Komposisi Media Tanam pada Ternik Bud Chip Tiga Varietas Tebu (Saccharum officinarum L.). Jurnal Produksi Tanaman.

Rahayu TB, Simanjuntak BH, Suprihati. 2014. Pemberian kotoran kambing terhadap pertumbuhan dan hasil wortel (Daucus Carota) dan bawang daun (Allium Fistulosum L) dengan budi daya tumpangsari. Jurnal Ilmu Pertanian. 26: 52-60.

Rizwan M. 2008. Evaluasi pupuk NPK dan pupuk organik terhadap pertumbuhan dan produksi tanaman kacang. Jurnal IImiah Abdi IImu. 3: 150-158.

Sarido AD. 2013. Uji empat jenis pupuk kandang terhadap pertumbuhan dan hasil tanaman cabai keriting (Capsicum annum L.). Agrifor, 12(1), 22-29.

Silvia M, Noor MS, Erhaka ME. 2012. Respon pertumbuhan dan hasil tanaman cabe rawit (Capsicum frutescent L.) terhadap pemberian pupuk kandang kotoran kambing pada tanah ultisol. Agroscientise. 19: 148-154.

S Rahman - Andi. Yogyakarta, 2010. Meraup Untung Bertanam Cabai Rawit dengan polybag.

Sofiarani, FN dan Erlina A. 2020. Pertumbuhan dan hasil Cabai Rawit (Capsicum frutescens L) Pada Berbagai Komposisi Media Tanam dalam skala Pot. Vegetalika. 2020. 9.(1): 292-304.

Souri, S. (2001). Penggunaan Pupuk Kandang Meningkatkan Produksi Padi. Laporan Penelitian. Instalasi Penelitian dan Pengkajian Teknologi Pertanian Mataram.

Supriyanto, A. (2012).Pengaruh Pemberian Pupuk Hayati (Biosfertilizer) dan Media Tanam Yang Berbeda Pada Tumbuhan dan Produktivitas Tanaman Cabe Rawit (Capsicum frutencens).

Sutedjo, MM, 1995. Pupuk dan Pemupukan. Rineka Cipta. Jakarta.

Tria Santari P., Arief H dan Suwarno. 2019. Pengaruh Pemberian Pelet dari Lumpur Kolam Ikan dan Kotoran Kambing pada Pertumbuhan dan Produksi Jagung Manis. Jurnal IImu Pertanian Indonesia (JIPI), Januari 2019. ISSN 0853-4217.

Qibtiyah, M., Hasan Kholiq dan Choirul A. 2021.Kajian Macam Jarak Tanam dan Dosis Pupuk Kandang Kambing Terhadap Pertumbuhan dan Produksi cabai Rawit (Capsicum frutencens). Agroradix Vol.5 No.1 ISSN: 26210665. 